Article

\title{
Effect of Anti Diabetic Drugs on Lipid Profile in Patients with Type 2 Diabetes Mellitus
}

\author{
Alaa H. Jawad 1, Zyad H. Al-Qaisi 2, Ammal E. Ibrahim ${ }^{3}$, Zainab S. Hallab ${ }^{1}$, \\ Abdualbasit Graisa ${ }^{4}$, Ahmed Al-Amiery ${ }^{5, *}$ and Emad Yousif ${ }^{1}$ \\ 1 Department of Chemistry, College of Science, Al-Nahrain University, Baghdad, Iraq; \\ alaaalqaisisma@gmail.com (A.H.J.); na0891@hotmail.com (Z.S.H.); \\ emad_yousif@hotmail.com (E.Y.) \\ 2 Department of Chemistry, College of Science, University of Al-Mustansiriyah, Baghdad, Iraq; \\ zyadalqaisi@yahoo.com \\ 3 Department of Pharmaceutical Chemistry, College of Pharmacy, Al-Nahrain University, \\ Baghdad, Iraq; dr.ammalalobaidi@yahoo.com \\ 4 Medical Technology Department, Faculty of Medical Technology, Misurata, Libya; \\ graisa61@yahoo.co.uk \\ 5 Environmental Research Center, University of Technology, Baghdad, Iraq \\ * Correspondence: dr.ahmed75@ukm.edu.my
}

\begin{abstract}
Diabetes mellitus (DM) has been defined as a group of metabolic diseases characterized by hyperglycemia resulting from defects in insulin secretion, insulin action, or both. This study includes (84) subjects, their age ranged from (40 to 54) years. (20) subjects were healthy chosen as control group and (64) patients with type 2 diabetes mellitus were divided into three groups according to their type of anti diabetic therapy: (23) newly diagnosed group without therapy (Group1), (20) with metformin therapy (Group2) and (21) with metformin plus glibenclamide therapies (Group3). In the study lipid profile level were quantitatively determine by enzymatic methods, in addition to that fasting plasma glucose (FPG), Glycated hemoglobin $(\mathrm{HbA} 1 \mathrm{c} \%)$ and body mass index (BMI) were identified in the patients. There is significant increase in the level of lipid profile in patients group. Metformin alone produce a non-significant favorable effect on all lipids profile parameters while metformin plus glibenclamide showed a significant reduction in TC and LDLC.
\end{abstract}

Kewwords: diabetes mellitus; metformin; glibenclamide and lipid profile

\section{Introduction:}

Diabetes mellitus (DM) has been defined as a group of metabolic diseases characterized by hyperglycemia resulting from defects in insulin secretion, insulin action, or both [1]. Insulin is a hormone produced in pancreas enable body cells to absorb glucose to turn into energy if the body cell do not absorb the glucose it will accumulates in its blood "hyperglycemia" The chronic hyperglycemia leading to various potential complication [2]. The new classification of DM has been proposed 
by American Diabetes Association (ADA) and World Health Organization (WHO). It comprises four etiological types: Type 1 diabetes (due to b-cell destruction, usually leading to absolute insulin deficiency), Type 2 diabetes (due to a progressive insulin secretary defect on the background of insulin resistance), Gestational diabetes mellitus (GDM) (diabetes diagnosed in the second or third trimester of pregnancy that is not clearly overt diabetes) [3]. It was previously called insulindependent diabetes mellitus (IDDM) or juvenile-onset diabetes. Type 1 diabetes develops when the body's immune system destroys pancreatic beta cells resulting in failure of insulin production. This form of diabetes usually strikes children and young adults, although disease onset can occur at any age. Type 1 diabetes accounts for $5-10 \%$ of all diagnosed cases of diabetes [4]. This type of diabetes usually presents acutely with hyperglycemic symptoms include polyuria, thirst, tiredness, weight loss and drowsiness usually denote impending ketoacidosis [5]. Type 2 diabetes: Named non-insulin dependent diabetes mellitus (NIDDM) or adult onset diabetes. It was account for $90-95 \%$ of those with diabetes. Type 2 diabetes mellitus is a heterogeneous disease which is characterized by variable degrees of insulin resistance, impaired insulin secretion and increased glucose production [6]. Insulin resistance occurs when the cells become less sensitive to the effects of insulin [7]. In continuation of previous studies [8-22], herein we are reporting study lipid profile level were quantitatively determining by enzymatic methods, in addition to that fasting plasma glucose (FPG), Glycated hemoglobin ( $\mathrm{HbA} 1 \mathrm{c} \%$ ) and body mass index (BMI) were identified.

\section{Patients and Control}

Sixty-four patients with type 2 diabetes mellitus were selected according to convenient non-random one and carried out by consecutive pooling of diabetic patients attending the National center of Diabetes in (AL-Mustansiria University) during the period from November 2014 to March 2015. The present study included 84 subjects were divided into four groups Group1: newly diagnosed (without therapy) (23), group 2: with metformin therapy (MT.) (21), group 3: with metformin plus glibenclamide therapy (MT. plus Glib.)(20), and 20 Healthy subjects were included in the study as a control group. Age, Duration of diabetes, BMI, and FPG were evaluate in the Sera of Type 2 diabetic subjects and control, the result was revealed:

Patients with renal failure, Cushing syndrome or hepatic diseases were excluded from the study after the clinical evaluation. Patients taking oral hypoglycemic agents other than metformin or glibenclamide and those taking drugs that may affect the results of the study had also been excluded. The sample for the assay were taken early in the morning between (8.30 and 11.00 A.M) while both patient and healthy subjects were relaxed and fasting for (12-14) hours. A careful history was obtained from patients including age, duration of diabetes, duration of taking treatment, family history, weight and height, type of treatment, other diseases and smoking. All patients were clinically examined; Pregnant patients 
were not enrolled. Evaluation of each patient is done by detecting the body mass index (BMI), levels of fasting plasma glucose(FPG), glycated hemoglobin $\mathrm{HbA} 1 \mathrm{c} \%$, lipid profile, and glucose-6-phosphatase activity(G-6-Pase).

\section{Collection of Blood samples}

From each subjects, $10 \mathrm{~mL}$ of blood were obtained by vein puncture, using a $10 \mathrm{ml}$ disposable syringes. The blood sample was divided into two aliquots; 2 \& $8 \mathrm{ml}$. The first aliquot blood was dispensed in a tube containing Ethylene Diamine Tetra acetic acid (EDTA), this blood mixed gently and used for HbA1c estimation, While the second aliquot was dispensed in a plain tube and left to clot at room temperature $\left(25^{\circ} \mathrm{C}\right)$, and then separated by centrifuge at (3000 rpm) for (10 $\mathrm{min})$ to collect serum and stored in the deep Freeze $\left(-20{ }^{\circ} \mathrm{C}\right)$ until the assay day.

The parameters measured be enzymatic methods: glucose kit supplied bySpinreact, Spain, Glucose-6-phophatase Enzyme from Cusabio, Chinam, Glycated hemoglobin $(\mathrm{GHb})$ from Infopia, Korea, HDL-Cholesterol, Total Cholesterol and Triglyceride from Randox, U.K.

\section{Statistical Analysis}

Statistical analysis was performed using SPSS (Statistical Packages for Social Sciences- version 17.1) and Microsoft Office Excel (Microsoft Office Excel for windows; 2007). Data were analyzed by using One Way Analysis of Variance (ANOVA) to calculate the p-value for healthy and other patients' groups. Student T-test was done also to compare means between groups. Pearson test was used to test the correlation between the assessed parameters. The results were presented as mean \pm standard error. Statistical significance was considered at the level of $(p \leq 0.01)$ and $(p \leq 0.05)$. 
Results and Discussion

Table (1) Clinical characteristics of three groups diabetic patients and control group.

\begin{tabular}{|c|c|c|c|c|c|}
\hline \multirow[t]{2}{*}{ Parameters } & \multicolumn{4}{|l|}{ Mean \pm SD } & \multirow[t]{2}{*}{ P-value } \\
\hline & $\begin{array}{l}\text { Control } \\
\text { group }\end{array}$ & $\begin{array}{l}\text { Group1 } \\
\text { Newly } \\
\text { diagnosed } \\
\end{array}$ & $\begin{array}{l}\text { Group } 2 \\
\text { MT. }\end{array}$ & $\begin{array}{l}\text { Group } 3 \\
\text { MT. plus } \\
\text { Glib. }\end{array}$ & \\
\hline Age (years) & $\begin{array}{ll}40.50 & \pm \\
8.18 & \end{array}$ & $\begin{array}{l}53.65 \pm 4.45 \\
\mathrm{a}\end{array}$ & $\begin{array}{ll}54.29 & \pm \\
3.47 \mathrm{~b} & \end{array}$ & $\begin{array}{l}53.70 \pm 2.69 \\
c\end{array}$ & $0.0001^{*}$ \\
\hline BMI $\left(\mathrm{Kg} / \mathrm{m}^{2}\right)$ & \begin{tabular}{ll|}
23.16 & \pm \\
2.87 & \\
\end{tabular} & $\begin{array}{l}27.15 \pm 3.66 \\
\mathrm{a}\end{array}$ & $\begin{array}{ll}25.98 & \pm \\
3.37 \mathrm{~b} & \\
\end{array}$ & $\begin{array}{l}26.38 \pm 3.89 \\
c\end{array}$ & $0.0025^{*}$ \\
\hline $\begin{array}{l}\text { Duration of } \\
\text { diabetic (years) }\end{array}$ & --- & --- & $3.09 \pm 1.03$ & $3.38 \pm 1.08$ & 0.4030 \\
\hline $\begin{array}{l}\text { Duration of } \\
\text { taking } \\
\text { treatment(years) } \\
\end{array}$ & --- & --- & $2.14 \pm 1.04$ & $2.70 \pm 1.11$ & 0.1059 \\
\hline FPG(mmole/L) & $4.67 \pm 0.39$ & $\begin{array}{l}12.00 \pm 2.34 \\
\mathrm{a}\end{array}$ & $\begin{array}{l}6.96 \pm 1.30 \\
b d\end{array}$ & $\begin{array}{l}7.70 \pm 1.23 \\
\mathrm{c} \mathrm{e}\end{array}$ & $0.0001^{*}$ \\
\hline
\end{tabular}

* significant using ANOVA test at 0.05 level of significance.

a) indicate significant difference between control and Group1.

b) indicate significant difference between control and Group2.

c) indicate significant difference between control and Group3.

d) indicate significant difference between Group1 and Group2.

e) indicate significant difference between Group1 and Group3.

f) indicate significant difference between Group2 and Group3.

Table (1) showed significant differences in age when comparing diabetics groups with control group. Body mass index were found to be elevated in diabetic groups under the study. This result was in agreement with Fadhil et al (2011) who have demonstrated, that BMI was elevated markedly in diabetic patients compared with non-diabetic subjects [23]. The results for the duration of diabetes and duration of treatment in group2 reported a no significant differences when compared with group3. In group1 FPG was higher than group2 and group3 this could be due to anti-diabetic drugs which reduce FPG. Metformin reduces blood glucose levels by inhibiting hepatic glucose production and reducing insulin resistance, particularly in liver and skeletal muscle [24]. Glibenclamide enhancing insulin secretion from the pancreas blocking hepatic glucose production and reduce glucose levels [25]. There was a non-significant difference between group2 and group3. This result was in agreement with Marwan M. (2013) who have demonstrated that there were a nonsignificant differences between fasting glucose of metformin treated group and those treated by a combination therapy of metformin plus glibenclamide [26]. 
Table (2) : Mean values of the studied parameters in three groups diabetic patients and control group.

\begin{tabular}{|c|c|c|c|c|c|}
\hline \multirow[t]{2}{*}{ Parameter } & \multicolumn{4}{|c|}{ Mean $\pm S D$} & \multirow{2}{*}{$\begin{array}{l}P \text { - } \\
\text { value }\end{array}$} \\
\hline & $\begin{array}{l}\text { Control } \\
\text { group }\end{array}$ & $\begin{array}{l}\text { Group1 } \\
\text { Newly } \\
\text { diagnosed }\end{array}$ & $\begin{array}{l}\text { Group } 2 \\
\text { MT. }\end{array}$ & $\begin{array}{l}\text { Group } 3 \\
\text { MT. plus } \\
\text { Glib. }\end{array}$ & \\
\hline HBA1c \% & $4.35 \pm 0.63$ & $9.39 \pm 1.24 \mathrm{a}$ & $\begin{array}{l}7.40 \pm 1.84 \\
\mathrm{~b} \mathrm{~d}\end{array}$ & $\begin{array}{l}7.09 \pm 1.02 \\
\mathrm{c} \mathrm{e}\end{array}$ & $0.0001^{*}$ \\
\hline $\begin{array}{l}\text { Cholesterol } \\
(\mathrm{mmole} / \mathrm{L})\end{array}$ & $4.06 \pm 0.89$ & $5.13 \pm 1.15 a$ & $4.45 \pm 1.44$ & $\begin{array}{l}3.78 \pm 1.29 \\
\mathrm{e}\end{array}$ & $0.0029^{*}$ \\
\hline $\begin{array}{l}\text { Triglyceride } \\
(\mathrm{mmole} / \mathrm{L})\end{array}$ & $1.36 \pm 0.45$ & $2.09 \pm 0.97 a$ & $1.64 \pm 0.71$ & $1.81 \pm 0.58$ & $0.0111^{*}$ \\
\hline HDL(mmole/L) & $1.40 \pm 0.31$ & $1.08 \pm 0.16 a$ & $\begin{array}{l}1.21 \pm 0.19 \\
b\end{array}$ & $\begin{array}{l}1.11 \pm 0.17 \\
\mathrm{c}\end{array}$ & $0.0001^{*}$ \\
\hline LDL(mmole/L) & $1.80 \pm 0.47$ & $\begin{array}{l}2.98 \pm 0.89 \\
\mathrm{a}\end{array}$ & $\begin{array}{l}2.57 \pm 1.22 \\
b\end{array}$ & $\begin{array}{l}1.82 \pm 1.27 \\
\mathrm{e}\end{array}$ & $0.0003^{*}$ \\
\hline $\begin{array}{l}\text { VLDL } \\
(\mathrm{mmole} / \mathrm{L})\end{array}$ & $0.618 \pm 0.09$ & $0.95 \pm 0.19 a$ & $0.745 \pm 0.14$ & $0.818 \pm 0.12$ & $0.0111^{*}$ \\
\hline
\end{tabular}

*significant using ANOVA test at 0.05 level of significance.

Table (2) showed that the mean of glycated hemoglobin was found to be statistically significant. The HbA1c \% level in group1 (newly diagnosed group) which do not take any type of anti-diabetic drugs has been statistically significant elevated as compared with those diabetic in group2 (with metformin therapy) and group3 (with metformin plus glibenclamide therapy). This result was in agreement with Krishna et al (2015) who have demonstrated that anti- diabetic drugs such as metformin and glibenclamide produced a significant decrease in $\mathrm{HbA} 1 \mathrm{c} \%$ levels compared to pre-treatment values [27]. On the other hand, there was a non significant difference between group2 and group3 this result is agreeing with Marwan (2013) who have demonstrated that there were a nonsignificant differences in $\mathrm{HbA} 1 \mathrm{c} \%$ levels between metformin treated group and those treated by a combination therapy of metformin plus glibenclamide [28].

This results in agreement with Reyadh et al (2012) who found that use of metformin / glibenclamide combination or metformin alone in the treatment of T2DM maintained cholesterol levels closer to normal levels and in combination therapy serum TC level was lower than metformin used alone [29]. Triglyceride results was found to be significantly elevated ( $\mathrm{x} \leq 0.05$ ) in group1(newly diagnosed group) when compared with control group this result in agreement with Attalah (2007) who found increase level of serum triglycerides in diabetic patients, which could be due to the increase of hepatic triglyceride synthesis [30]. Group2 (with metformin therapy) and group3(with metformin plus glibenclamide therapy) showed a nonsignificant differences when compared with group1 and control group these results 
were in agreement with Kassim (2011) who found that metformin and glibenclamide therapies produces a non-significant favorable effect on serum triglyceride [31].

Type 2 diabetes is characterized by low HDL cholesterol (HDL-C) and HDL dysfunction ${ }^{17}$. The precise cause of the low HDL-C in type 2 diabetes is not known but may be the consequence of insulin resistance, augmented very low density lipoprotein production and increased activities of cholesteryl ester transfer protein and hepatic lipase [32]. Cagatay et al (2011) found that using metformin as a mono therapy or combination with glibenclamide in type 2 diabetics produce a nonsignificant effect on HDL-C [33]. The results of serum low density lipoprotein for group1 and group2 diabetic patients was found to be significantly different $(p \leq 0.05)$ when compared with control group. Singh and Kumar (2011) found that the level of LDL significantly higher in type 2 diabetics [34]. Increased elimination of lipids and apolipoproteins from VLDL particles results in the increased production of intermediate density lipoprotein (IDL) and LDL [35]. Dailey et al (2002) found that combination therapy of metformin and glibenclamide shows a favorable effect on LDL-C levels and closer to that of nondiabetic subjects [36]. Petrovic et al (2010) study revealed a significant elevation in VLDL-C when compared diabetic patients with controls. This may be due to insulin resistance has striking effects on lipoprotein size and subclass particle concentrations for VLDL and that lead to increased hepatic secretion of VLDL-C in type 2 diabetic patients [37], while Reyadh et al (2012) who found a no significant difference between metformin and metformin plus glibenclamide treated groups compared with control group [38-41].

\section{Conclusions:}

Metformin alone produce a non-significant favorable effect on all lipids profile parameters while metformin plus glibenclamide showed a significant reduction in TC and LDL-C.

\section{References}

1. American Diabetes Association. Diagnosis and Classification of Diabetes Mellitus, Diabetes Care. 37(1) (2014) S81- S90.

2. K. Rothe Diabetes Treatment-Bridging the Divide. The New England Journal of Medicine. 356 (15) (2007) 1499-501.

3. American Diabetes Association. Classification and Diagnosis of Diabetes. Diabetes Care. 38(1) (2015)S8- S16.

4. L. Jane, K. MSue, M. Lori, L. Anne. Type 1 Diabetes through the Life Span: A Position Statement of the American Diabetes Association, Diabetes Care, 37(7) (2014) 2034- 2054.

5. L. Tom, T. Ken, G. Matthias. Type 1 Diabetes: Etiology, Immunology, and Therapeutic Strategies. Physiological Review. 91(2011) 79-118.

6. K. Nowotny, T. Jung, A. Höhn, D. Weber, T Grune. Advanced glycation end products and oxidative stress in type 2 diabetes mellitus. Biomolecules. 5(1) (2015) 194-222. 
7. H. Akter. Review on Diabetics and anti-diabetic drugs. Asian Journal of Pharmaceutical Technology \& Innovation. 2 (4) (2014) 1-16.

8. A. Al-Amiery A. Kadhum and A. Mohamad. Antifungal Activities of New Coumarins. Molecules 2012;17:5713-5723.

9. A. Al-Amiery, K. Saour, D. A-Duhaidahawi, Y. Al-Majedy, A. Kadhum. Comparative Molecular Modelling Studies of Coumarin Derivatives as Potential Antioxidant Agents. Free Radicals and Antioxidants, 20177 (1), 3135

10. Y. Al-Majedy, A. Al-Amiery, A. Kadhum, A. Mohamad, Antioxidant Activities of 4-Methylumbelliferone Derivatives. PLoS ONE. 2016;11:1-13.

11. A. Al-Amiery, Y. Al-Majedy, K. Kadhum, A. Mohamad, Synthesis of new coumarins complemented by quantum chemical studies. Research on Chemical Intermediates. 2016; 42:3905-3918

12. Y. Al-Majedy, D. Al-Duhaidahawi, K. Al-Azawi, A. Al-Amiery,A. Kadhum, A.Mohamad, Coumarins as Potential Antioxidant Agents Complemented with Suggested Mechanisms and Approved by Molecular Modeling Studies. Molecules 2016;21:135-145.

13. A. Al-Amiery, Y. Al-Majedy. D. Al-Duhaidahawi, A. Kadhum, A. Mohamad, Green Antioxidants: Synthesis and Scavenging Activity of CoumarinThiadiazoles as Potential Antioxidants Complemented by Molecular Modeling Studies. Free Radicals and Antioxidants, 2016; 6(2): 173-177

14. A. Al-Amiery, Y. Al-Majedy, A. Kadhum, A. Mohamad A (2015) Novel macromolecules derived from coumarin: synthesis and antioxidant activity. Sci Rep 5: 11825

15. A. Kadhum, A. Mohamad A. Al-Amiery, Takriff MS. Antimicrobial and Antioxidant Activities of New Metal Complexes Derived from 3Aminocoumarin,journal of Molecules 2011;16:6969-6984.

16. Y. Al-Majedy Y, A. Al-Amiery, A. Kadhum, Hydrogen Peroxide Scavenging Activity of Novel Coumarins Synthesized Using Different Approaches. PLoS ONE 10 (7), e0132175 (2015)

17. A. Al-Amiery, H.Kadhum, A. Obayes, B Mohamad. Synthesis and antioxidant activities of novel 5-chlorocurcumin, complemented by semiempirical calculations. Bioinorganic chemistry and applications 2013.

18. M. Alias, C. Shakir, F. Mohammad, E. Yousif, Synthesis and cytotoxic effect on RD cell line of $\mathrm{Pd}(\mathrm{II})$ and $\mathrm{Cu}(\mathrm{II})$, Journal of Saudi Chemical Society, 2016, 20, 24-32.

19. Z. Hussain, Z. Fadhil, H. Adil, M. Khalaf, B. Abdullah, E. Yousif, Schiff's Bases Containing Sulphamethoxazole Nucleus, Research Journal of Pharmaceutical, Biological and Chemical Sciences, 2016(3), 7, 1500-1510.

20. EY Alaa H. Jawad, Ammal E. Ibrahim, Raghda Alsayed, Zainab Salih Hallab, Study the Impact of Glucose-6-phosphatase Activity in Type 2 Diabetic Patients and Non Diabetic Counterparts, Preprint, 2016, 1, 1-6.

21. M. Khalaf, D. Zageer, Z. Hussain, H. Adil, S. Mohammed, E. Yousif, Guanidine Group: Definition and Pharmaceutical Applications, Research 
Journal of Pharmaceutical, Biological and Chemical Sciences, 2016, 7(5), 10261031.

22. F. Hassan, A. Abdul Hameed, A. Alshanon, B. M. Abdullah, H. Zaman Huri, N. Hairunisa, E.Yousif, Antitumor Activity for Gold (III) Complex by High Content Screening Technique (HCS) and Cell Viability Assay, Asian Journal of Biochemistry, 2015, 10 (6), 252-266.

23. J. Fadhil, G. Ammar, H. Tariq. Effects of Type-2 Diabetes Mellitus on Serum Leptin, Insulin, Interlukin-8, and Lipid Profile. Karbala Journal of Medicine . 4(1) (2011) 1011-1018.

24. F. Alkhalaf, A.T. Soliman, V. De Sanctis. Metformin Use in Adolescents: Old and New Therapeutic Perspectives, Journal of Diabetes \& Metabolism.5(12) (2014)472.

25. R. Ibrahim, Diabetes mellitus type II: review of oral treatment options. International Journal of Pharmacy and Pharmaceutical Sciences. 2(1 ) (2010) 21-30.

26. M. Marwan. Effect of metformin, glibenclamide and insulin on lipid profile in type 2 diabetic patients. Tikrit Journal of Pharmaceutical Sciences. 9(2) (2013) 262-269.

27. K. Krishna, B. Sowmya, B. Mamata, M.P. Naidu. Effects of Glibenclamide and Glimepiride Compared in Type II DM Patients in Accordance with Lipid Parameters, ESF and Glycated Haemoglobin. British Journal of Applied Science \& Technology. 10(3) (2015) 1-10.

28. L. Al-Naama, S. Ajlan, M. Mahmood. Evalution of lipid and lipoprotein profile in patients with type 2 diabetes. The Medical Journal Basra university. 28(1) (2010) 28-32.

29. H. Reyadh. Effects of Metformin, Glyburide and their Combination on Lipid Profile in NIDDM Patients. Medical Journal of Babylon. 9(4) (2012) 936-945.

30. S. Attalah. Markers for side complications amoung diabetic mellitus patients , ph. D. thesis, Department of Natural Science and life, Algeria university. (2007)

31. S. Kassim Comparative effect of Metformin and Glibenclamide on Lipid profile in type 2 Diabetic Patients. Tikrit Journal of Pharmaceutical Sciences. 7(1) (2011) 50-64

32. G. P. Fadini Iori, E. M.C. Marescotti, S.V. de Kreutzenberg, A. Avogaro. Insulin-induced glucose control improves HDL cholesterol levels but not reverse cholesterol transport in type 2 diabetic patients. Atherosclerosis. 235(2) (2014) 415-417.

33. P. J. Barter. The causes and consequences of low levels of high density lipoproteins in patients with diabetes. Diabetes \& metabolism journal. 35(2) (2011)101-106.

34. P. Cagatay, B. Susleyici-Duman, H. Alasya, A. Ipbuker. Effects of oral antidiabetic drugs over lipid parameters in Turkish type 2 diabetes patients. Acta Medica Academica. 38(2) (2009) 77-85. 
35. G. Singh Kumar. Relationship among $\mathrm{HbA1c}$ and lipid profile in Punajbi type 2 diabetic population. Journal of Exercise Science and Physiotherapy. 7(2) (2011) 99-102.

36. I. J. Goldberg, Lipoprotein lipase and lipolysis: central roles in lipoprotein metabolism and atherogenesis. Journal of lipid research. 37(4) (1996) 693707.

37. G. E. Dailey, P. Mohideen, F.T. Fiedorek, Lipid effects of glyburide/metformin tablets in patients with type 2 diabetes mellitus with poor glycemic control and dyslipidemia in an open-label extension study. Clinical therapeutics. 24(9) (2002) 1426- 438.

38. J. Petrovic, M. Maldenovic, A. Djukic. Sipetic Lipid profile in type 2 diabetic patients in Kragujevac, Endocrine Abstracts. 22 (2010) P262.

39. M. Rosenbaum, R. L. Leibel. Role of leptin in energy homeostasis in humans. Journal of Endocrinology. 223(1) (2014) T83-T96.

40. S. A. Mohammed, A.E. Ibrahim, A. Hasan, E. Yousif, Investigation on The Effect of Phytosterols on Lipid Profile, Journal of Pharmaceutical and Medicinal Research 2(2) (2016) 60-61.

41. A. Ibrahim, A. Alwas, A. Hasan, E. Yousif, Dr. Ben Kim Supplement Impact on Cholesterol and Triglycerides, Journal of Pharmaceutical and Medicinal Research 1(1): (2015) 9-10.

(C) 2016 by the authors; licensee Preprints, Basel, Switzerland. This article is an open access article distributed under the terms and conditions of the Creative Commons by Attribution (CC-BY) license (http://creativecommons.org/licenses/by/4.0/). 